\title{
Estudo da malha aérea e infraestrutura do complexo aeroportuário de Fortaleza após privatização
}

\section{Study of the aerial network and infrastructure of the airport complex in Fortaleza after privatization}

\section{Estudio de red aérea e infraestructura del complejo aeroportuario de Fortaleza después de la privatización}

\section{Étude du réseau aérien et des infrastructures du complexe aéroportuaire de Fortaleza après la privatisation}

\section{Resumo}

Bruno da Silva Sales Universidade de Fortaleza Unifor bruno.silva0374@hotmail.com

Paulo Victor Carneiro

Araujo

paulovictor1ca@edu.unifor.br Universidade de Fortaleza Unifor

\section{Nelson Bezerra Ferreira} Júnior

nbfj@hotmail.com

Universidade de Fortaleza Unifor

Viviane Adriano Falcão viviane.afalcao@ufpe.br Universidade Federal de Pernambuco
Um aeroporto consiste em uma instalação em solo dotada de sistemas para suporte de operações de aeronaves, especialmente pousos e decolagens. O presente estudo visa realizar uma pesquisa bibliográfica e informativa da malha aérea distribuída em seus diversos níveis, quais sejam: regional, nacional e internacional. Também avalia as características da infraestrutura do aeroporto de Fortaleza, tais como a classe e aeronave crítica, sendo reportadas as melhorias realizadas na reforma de ampliação, prospectando o atendimento de uma maior demanda, com maior fluidez, gerando indicadores positivos ao parque aeroportuário. Por fim, com a prospecção do aumento no fluxo de passageiros no modal aéreo que passa pelo aeroporto de Fortaleza (embarque, desembarque, conexão) no final da concessão, que ocorrerá no ano de 2046, mostra-se a necessidade de manter investimentos contínuos para manter a qualidade nos serviços prestados e garantir o desenvolvimento do setor no parque aeroportuário de Fortaleza.

Palavras-chave: Aeroporto. Ampliação. Malha aérea. Infraestrutura. Privatização.

\begin{abstract}
An airport consists of a ground installation with systems to support aircraft operations, especially landings and takeoffs. The present study aims to carry out a bibliographic and informative survey of the air network distributed at its different levels, namely: regional, national and international. It also assesses the characteristics of the airport infrastructure in Fortaleza, such as the class and critical aircraft, and the improvements made in the expansion reform are reported, aiming at meeting a greater demand, with greater fluidity, generating positive indicators for the airport park. Finally, with the prospect of an increase in the flow of passengers in the air transport through Fortaleza airport (boarding, landing, connection) at the end of the concession, which will take place in the year 2046, there is a need to maintain continuous investments for maintain the quality of the services provided and guarantee the development of the sector in the airport park of Fortaleza.
\end{abstract}

Keywords: Airport. Enlargement. Aerial network. Infrastructure. Privatization.

\section{Resumen}

Un aeropuerto consiste en una instalación en suelo dotada de sistemas para soporte de operaciones de aeronaves, especialment e aterrizajes y despegues. El presente trabajo tiene el objetivo de realizar una investigación bibliográfica e informativa de la red aérea repartida en sus distintos niveles, se anellos: regional, nacional e internacional. También 
evalúa las características de la infraestructura del aeropuerto de Fortaleza, tales como la clase y aeronavecrítica, reportando las mejorías realizadas en la reforma de ampliación, prospectando el atendimiento de una mayor demanda, con mayor fluidez, generando indicadores positivos al parqu e aeroportuario. Por fin, con la prospección del incrementoen el flujo de pasajeros en el modal aéreo que pasapor el aeropuerto de Fortaleza (embarque, desembarque, conexión) al final de la concesión, que ocurrirá en el año de 2046, se muestra la necesidad de manten erin versiones continuas para mantener la calidad en los servicios ofrecidos y garantizar el desarrollo del sector en el parque aeroportuario de Fortaleza.

Palabras-clave: Aeropuerto. Ampliación. Red aérea. Infraestructura. Privatización.

\section{Résumé}

Un aéroport est une installation au sol qui a des systèmes pour soutenir les opérations afférentes aux aéronefs, en particulier les atterrissages et les décollages. La présente étude vise à réaliser une étude bibliographique et informative du réseau aérien réparti à ses différents niveaux, à savoir: régional, national et international. Cette étude évalue également les caractéristiques de l'infrastructure aéroportuaire de Fortaleza, telles que la classe et l'avion critique, au même temps que les améliorations de la réforme d'expansion sont rapportées, en visant à répondre à une demande plus importante, avec une plus grande fluidité, générant des indicateurs positifs pour le parc aéroportuaire. Enfin, avec la perspective d'une augmentation du flux de passagers dans le transport aérien via l'aéroport de Fortaleza (embarquement, débarquement, correspondance) à la fin de la concession, en 2046, il est possible d'apercevoir la nécessité de maintenir des investissements continus pour maintenir la qualité des services fournis et garantir le développement du secteur dans le parc aéroportuaire de Fortaleza.

Mots-clés: Aéroport. Élargissement. Réseau aérien. Infrastructure. Privatisation

\section{Introdução}

O produto interno bruto do Brasil é um dos fatores que mais influenciam no crescimento da demanda pelo modal aéreo (FALCÃO, 2013). A frequência do transporte aéreo no Brasil se aproxima a das nações desenvolvidas, passando de 0,3 para 0,7 viagem/ habitante por ano, de acordo com o Banco Nacional (2010).

Existem diversos hubs espalhados pelo território brasileiro, que possuem uma função estratégica para a continuidade da aviação civil. O aeroporto de Fortaleza também está entre os mais movimentados em número de passageiros, tenso sido classificado como o $3^{\circ}$ mais movimentado no Nordeste e $7^{\circ}$ entre todos os aeroportos brasileiros no ano de 2017 (INFRAERO, 2017).

Uma grande parte dos terminais aeroviários do Brasil se encontra em situação de operação elevada ou, em casos mais extremos, superior à capacidade de demanda máxima, como mostrado na Fig. 1, com a elevação do modal aéreo por conta do barateamento dos preços das passagens aéreas e do crescimento econômico brasileiro, que ocorreu no ano de 2013 (exemplificado pelo valor de 3\% do aumento do PIB nacional) e no ano de 2014, estagnando-se no ano de 2015 (quando ocorreu uma retração), como apresentado na Tab. 1, tornando a infraestrutura aeroportuária um gargalo na aviação civil a ser superado, pois não acompanhou o crescimento de passageiros que utilizam o modal aéreo com frequência. A aviação civil, por sua vez, está fortemente relacionada com o crescimento do PIB nacional e, caso a economia continue a crescer, a problemática da infraestrutura aeroportuária pode se encontrar em uma situação bem pior (LIMA, 2013). 
Figura 1 - Histórico de capacidade dos aeroportos do Brasil.

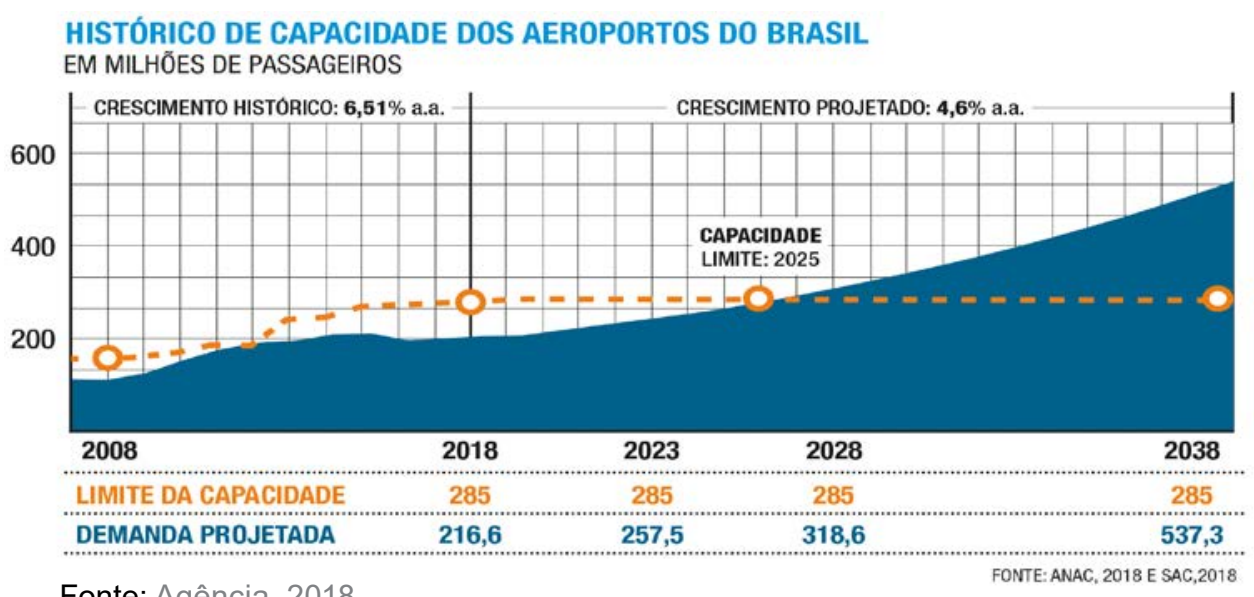

Tabela 1 - Evolução do PIB nacional.

\begin{tabular}{ccc}
\hline Ano & PIB Nacional & Crescimento (\%) \\
\hline 2009 & $\mathrm{RS} 3.333 .039 .355 .300,00$ & $-0,13 \%$ \\
2010 & $\mathrm{R} \$ 3.885 .847 .000 .000,00$ & $7,53 \%$ \\
2011 & $\mathrm{R} \$ 4.376 .382 .000 .000,00$ & $3,97 \%$ \\
2012 & $\mathrm{R} \$ 4.814 .760 .000 .000,00$ & $1,92 \%$ \\
2013 & $\mathrm{R} \$ 5.331 .618 .000 .000,00$ & $3,00 \%$ \\
2014 & $\mathrm{R} \$ 5.778 .954 .000 .000,00$ & $0,50 \%$ \\
2015 & $\mathrm{R} \$ 5.995 .787 .000 .000,00$ & $-3,55 \%$ \\
2016 & $\mathrm{R} \$ 6.267 .205 .000 .000,00$ & $-3,31 \%$ \\
2017 & $\mathrm{R} \$ 6.553 .843 .000 .000,00$ & $1,06 \%$ \\
2018 & $\mathrm{R} \$ 6.827 .586 .000 .000,00$ & $1,12 \%$ \\
\hline
\end{tabular}

Fonte: IBGE, 2018.

Levando em consideração os fatos apresentados e o crescimento do uso do modal aéreo, o presente estudo visa fazer uma análise documentativa das melhorias na infraestrutura do sitio aeroportuário após a privatização, mostrando o que mudou e, em paralelo a isso, avaliar as rotas aéreas nos cenários regional, nacional e internacional.

\section{Turismo e economia do Ceará}

O estado tem obtido melhoria na economia, consequência de fatores como os incentivos do governo na instalação de indústria, a redução ou até isenção de impostos e doação de terrenos, conseguindo obter a atração de mais de 600 empresas nacionais e estrangeiras para o estado cearense num intervalo de tempo de seis décadas, considerando o período de 1950 até 2010. A economia cearense teve uma estimativa do valor de seu PIB igual a $\mathrm{R} \$ 147,89$ bilhões em 2017 , com uma renda per capita de $\mathrm{R} \$ 855,00$, classificando a economia cearense com a terceira mais forte do Nordeste, com uma participação no PIB nordestino de 15,5\%, ficando atrás apenas do estado da Bahia, com representatividade no PIB nacional de 28,2\%, e Pernambuco, com 19\% para o ano de 2017 (IBGE, 2018).

De acordo com Soares (2017), em um estudo avaliativo da divisão do PIB cearense, no final do ano de 2016, o setor dos serviços é o principal item da economia do Ceará, sendo responsável por $76,1 \%$ do PIB do 
estado, seguido pelas áreas da indústria e agropecuária, com $19,2 \%$ e 4,7\%, respectivamente, em que o setor de indústria continua a perder participação para o setor de serviços. Algumas das atividades mais latentes do setor de serviços estão relacionadas com o turismo, a prestação de serviços às famílias e empresas, como manutenção de equipamentos de informática, comunicação social, clínicas estéticas, imobiliárias, instituições financeiras e o comércio. Este último é um dos mais importantes de todos os segmentos em que o setor serviços se divide. Tão importante como o comércio para a economia do Ceará, o turismo movimenta a economia de passageiros. Hoje, o Ceará recebe quase três milhões de turistas por ano. Essa atividade atrai grandes redes de hotéis, que se localizam, principalmente, na região litorânea da capital cearense. Com muitos pontos turísticos, a capital cearense é o lugar mais procurado durante as férias (FRANCISCO, 2018).

O estado do Ceará, por sua grande zona costeira, que banha vários municípios do estado, possui como atrativo as praias da região litorânea, que possibilitam a prática de esportes aquáticos, além de outros fatores que trazem muitos turistas. Entretanto vale salientar que, a maior parte desse fluxo de passageiros ocorre apenas nos períodos de alta estação, caracterizado pelas férias de inverno e verão, tornando o fluxo de passageiros muito sazonal no quesito turístico (DANTAS, 2002).

\section{Estudo do aeroporto de Fortaleza}

Existe no território brasileiro um total de 2.499 aeroportos e aeródromos, de todos os tamanhos (INFRAERO, 2019), classificando o Brasil como a segunda nação do mundo com a maior rede de aeroportos, sendo superado apenas pelos EUA, com um total de 5.146 aeroportos. Do total de 67 aeroportos geridos pela Empresa Brasileira de Infraestrutura Aeroportuária (Infraero), 31 são internacionais e os 36 demais são domésticos, conforme dados de 2009. Nesse mesmo ano, os aeroportos foram responsáveis pela movimentação de 128,1 milhões de passageiros e 1.114,8 mil toneladas de cargas (BARAT, 2012).

Os aeroportos geram seus lucros a partir de duas fontes, sendo a primeira delas as tarifas aeroportuárias de embarque, que incidem sobre os passageiros, a tarifa de pouso e permanência de aeronaves e conexão, que atuam sobre as companhias aéreas, além de uma série de tarifas de serviços prestados. A outra fonte de receita de um aeroporto é advinda das áreas comerciais providas das lojas de varejo. Inclusive, esse é um dos motivos pelo qual é tão importante realizar o check-in o mais rápido possível, permitindo que os passageiros tenham mais tempo para fazerem compras (BARAT, 2012). Esse foi um dos motivos da abertura de 31 novos pontos comerciais, totalizando 120 no aeroporto de Fortaleza.

A criação de um aeroporto está relacionada com a questão das rotas de aeronaves, a posição geográfica e a viabilidade econômica. Descobrir para quais cidades as companhias aéreas desejam que suas frotas desembarquem é um grande dilema, pois depende de para onde as pessoas querem ir e do quanto elas estão dispostas a pagar. Para obter esses dados valiosos, muitas empresas de pesquisa de mercado obtêm tais informações através de sites e aplicativos de buscas de rotas feitas pelos seus usuários.

O aeroporto de Fortaleza, da mesma forma que vários outros aeroportos brasileiros, passa por problemas decorrentes da atual infraestrutura não ser suficiente para manter a demanda com uma fluidez adequada, mesmo operando quase em sua capacidade máxima. Ocorreram importantes eventos esportivos no Brasil, ao longo da última década, sendo eles, a Copa das Confederações e a Copa do mundo de 2014, que alavancou um aumento na demanda no aeroporto por Fortaleza ser uma das cidades sedes dos jogos esportivos e dos jogos olímpicos que ocorreram em 2016, este último não demonstrando ter impacto na demanda do aeroporto, obviamente por ter se concentrado no Rio de Janeiro. Além desses eventos, notou-se um aumento expressivo nos anos de 2018 e 2019, que trouxe um novo recorde devido à inserção do novo hub da Air France, que movimentou demasiadamente o transporte aéreo internacional. Estes e outros fatores foram responsáveis por incrementar a aviação civil executiva e comercial no aeroporto de Fortaleza. Dessa forma, nota-se a necessidade do aumento da capacidade do sítio aeroportuário de Fortaleza. A Tabela 2, a seguir, mostra a movimentação do PAX total no aeroporto de Fortaleza ao longo dos anos. 
Tabela 2 - Movimentação anual nos últimos 10 anos no aeroporto de Fortaleza.

\begin{tabular}{lc}
\hline Ano & Movimento de passageiros \\
\hline 2009 & 4.061 .601 \\
2010 & 5.000 .519 \\
2011 & 5.488 .949 \\
2012 & 5.888 .021 \\
2013 & 5.885 .500 \\
2014 & 6.418 .502 \\
2015 & 6.275 .503 \\
2016 & 5.643 .538 \\
2017 & 5.899 .311 \\
2018 & 6.618 .364 \\
2019 & 7.196 .101 \\
\hline
\end{tabular}

Fonte: BRASIL, 2018.

\section{Caracterização do aeroporto}

\section{1 História do aeroporto}

Durante o período da Segunda Guerra Mundial (1939-1945), foi construída, em Fortaleza, uma pista de pousos e decolagens localizada no bairro Alto da Balança. A pista tinha cerca de 2.100 metros, sendo ampliada, em 1963, para 2.545 metros. A Base do Cocorote, como era chamada, recebeu o nome de Aeroporto Pinto Martins em 13 de maio de 1952, em homenagem ao cearense Euclides Pinto Martins, o piloto que realizou o primeiro voo entre Nova York e Rio de Janeiro, com um hidroavião, entre setembro de 1922 e fevereiro de 1923 (MELO, 2017).

O primeiro terminal de passageiros foi construído em 1966, com uma área de aproximadamente 8.200 $\mathrm{m}^{2}$ e capacidade para atendimento de 900 mil passageiros por ano. Após a inauguração de um novo terminal, que ocorreu em 7 de fevereiro de 1998, só então o aeroporto foi classificado como internacional, com uma localização geográfica privilegiada como possível ponto de entrada da Europa e América do Norte, também sendo excelente para os fortalezenses por estar a cerca de quinze minutos do centro da capital cearense. A Infraero começou a administrar o complexo aeroportuário a partir do dia 7 de janeiro de 1974. Novas obras de ampliação tiveram início em junho de 2012, cuja previsão de entrega era fevereiro de 2017, entretanto, em decorrência de sucessivos atrasos, não foram entregues (PEREIRA, 2018).

\section{2 Classificação do aeroporto}

De acordo com a RBAC 154, regida pela AGÊNCIA, (2019), a classe de um aeroporto é definida de acordo com o número de passageiros, sendo o cálculo feito com a média aritmética dos passageiros efetivos no período de análise. Vale salientar que o período de análise equivale ao tempo de três anos, anteriores ao ano atual, em que o estudo foi realizado. A classificação com relação ao número de passageiros efetivos, segundo a RBAC 154 da AGÊNCIA, (2019), é:

a) Aeroporto com classe I - número de passageiros efetivos inferior a 200.000;

b) Aeroporto com classe II - número de passageiros efetivos igual ou superior a 200.000 e inferior a 1.000.000;

c) Aeroporto com classe III - número de passageiros efetivos igual ou superior a 1.000 .000 e inferior a 5.000.000;

d) Aeroporto com classe IV - número de passageiros efetivos igual ou superior a 5.000.000. 
Segundo dados do anuário estatístico operacional da Infraero para os anos de 2015, 2016, 2017, o aeroporto teve uma média de passageiros superior a 5.000.000, como pode ser observado na Tab. 3. Então, conclui-se que o aeroporto de Fortaleza se classifica como um aeródromo de classe IV.

\section{3 Aeronave crítica}

Segundo a RBAC 139 da AGÊNCIA (2012), a aeronave crítica é tida como a aeronave que tem a possibilidade de entrar em operação no aeroporto e que necessitadas maiores exigências em termos de dimensionamento da infraestrutura aeroportuária, de acordo de suas características físicas e operacionais. A ANAC, usa um código de referência, associando-o ao modelo da aeronave, para identificar a aeronave crítica. O código de aeronave crítica para o Aeroporto de Fortaleza era 4E antes do início da reforma, o que significava dizer que poderiam pousar aeronaves como o Airbus A340 ou o Boeing 747-400. Mesmo com a ampliação da pista de 2.545 metros para 2.755 metros, o código da aeronave crítica continuaria sendo $4 \mathrm{E}$, não podendo receber aeronaves como o Airbus A380-800 e o Boeing 747-8, que precisam de 2.779 e 3.070 metros de comprimento de pista, respectivamente, para fazer pousos e decolagens com segurança, de acordo com informações da ANAC. Entretanto uma emenda no RBAC 139 de número 2 classificou o aeroporto de Fortaleza como 4F, de modo que, em dois momentos, já chegou a receber uma aeronave modelo An-124, ou seja, o aeroporto de Fortaleza gozará de uma infraestrutura adequada para receber aeronaves do tipo A380800 , Boeing 747-8 e similares. Um dos possíveis motivos pelos quais a reforma não ampliou a pista até obter a elevação do seu código de aeronave crítica, sem a necessidade da emenda, foi a limitação existente quanto às dimensões do sítio aeroportuário.

\section{A concessão}

O aeroporto de Fortaleza entrou na lista de concessões feita pelo Estado brasileiro com mais três aeroportos, sendo eles os aeroportos de Salvador (BA), Florianópolis (SC) e Porto Alegre (RS). A concessão do aeroporto aconteceu por meio de um decreto presidencial ocorrido em 2017. O valor arrematado pelo leilão do aeroporto de Fortaleza foi de $\mathrm{R} \$ 425$ milhões, com ágio de $18,5 \%$, pagos à vista no momento da assinatura do contrato para uma concessão de 30 anos, pelo grupo Fraport AG Frankfurt Airport Services, localizado na Alemanha. O grupo é responsável por gerenciar aeroportos nos cinco continentes habitados do planeta (AGÊNCIA, 2019).

O questionamento a respeito se é ou não um bom negócio ter em grande maioria empresas públicas é muito relativo, pois, olhando para o cenário internacional, existem países com grande número de privatizações, como o exemplo da França, e países com a maioria das empresas como estatais, como é o caso da Singapura e Noruega, e ambos deram certo. Entretanto vale ressaltar que, existem empresas em setores considerados estratégicos para a defesa e economia de uma nação que deveriam permanecer estatizados para o bem maior do povo e garantia da soberania do país.

Nos últimos anos, o governo tem adotado medidas para privatização de muitas estatais, as quais englobam os aeroportos, principalmente, os internacionais. Tal medida deve ser avaliada com mais cautela, tendo em vista que os aeroportos regionais, por terem um quadro menor de fluxo de passageiros, tendem a ser deficitários, motivo pelo qual, os aeroportos regionais não são objeto de interesse para iniciativa privada para concessão. Com as privatizações em grande escala, pode-se chegar ao ponto em que a Infraero acabe aumentando o gerenciamento de aeroportos de pequeno porte, como é o caso dos aeroportos regionais, que não geram lucro favorável para ela se manter. Uma possível solução seria a concessão em bloco de um aeroporto deficitário com outro superavitário.

\section{1 A reforma}

O aeroporto passou por uma reforma de ampliação, que contemplava o acréscimo de 210 metros na pista de pousos e decolagens $13 / 31$, passando a ter uma extensão total de 2.755 metros, além da expansão 
do terminal de passageiros, com abertura de oito novas pontes, totalizando quinze pontes de embarques, e a adequação no sistema viário e de vias de taxiamento, sendo também inclusas oito posições para estacionamento de aeronaves comerciais, totalizando vinte e seis. O término das obras de ampliação e revitalização da infraestrutura do parque aeroportuário ocorreu em março de 2020 , dois meses antes do período inicialmente previsto que era em maio do mesmo ano, que totalizou uma área de terminal de passageiros de $70.000 \mathrm{~m}^{2}$, e antes era de apenas $35.660 \mathrm{~m}^{2}$, realizada pelo consórcio das empresas Método e Passarelli, contabilizando um custo de projeto e execução de aproximadamente $\mathrm{R} \$ 800,00$ milhões (INFRAERO, 2019). A Figura 2 mostra a projeção horizontal das novas áreas edificadas no aeroporto.

Figura 2 - Comparação da atual área com a nova área do aeroporto.

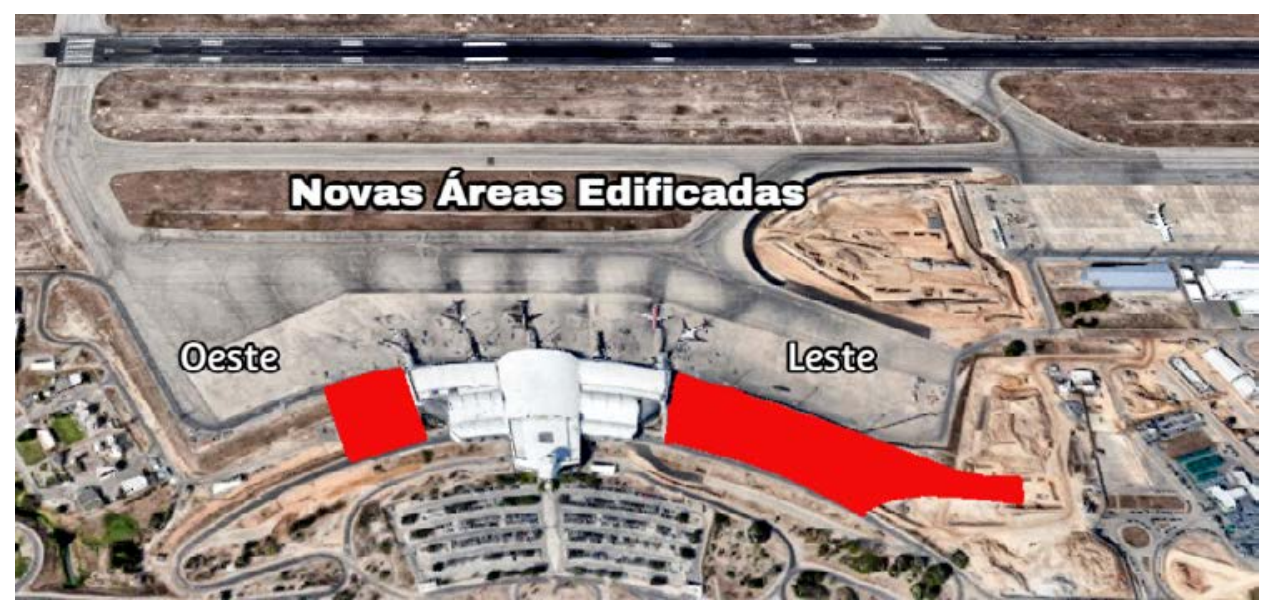

Fonte: FRAPORT, 2019.

\section{Análise da malha}

O aeroporto de Fortaleza atende às demandas da aviação regional, nacional e internacional com origem, conexão e destino no aeroporto de Fortaleza. Cada uma dessas demandas tem o seu peso no fluxo total de passageiros. É valido ressaltar que as companhias mudam suas rotas constantemente a depender da lucratividade e operacionalidade da mesma, sendo, portanto, algumas altamente intermitentes. A Figura 3 mostra a distribuição por tipo de rota no período de agosto de 2018 a agosto de 2019, em que se constata que a aviação nacional é responsável majoritária pela demanda aeroportuária de Fortaleza.

Figura 3 - Distribuição por classe de rota.

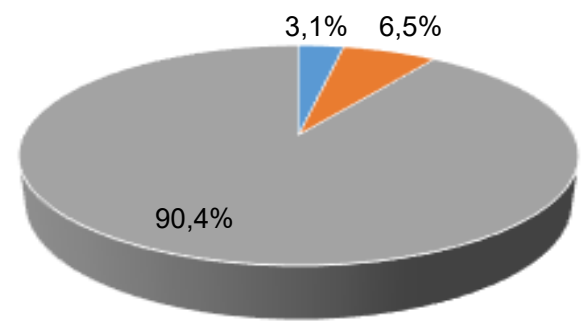

Voos partindo de Fortaleza com destino regional

- Voos partindo de Fortaleza com destino internacional

Voos partindo de Fortaleza com destino nacional

Fonte: BRASIL, 2018. 
As companhias aéreas de transporte de passageiros que possuem rotas para o aeroporto de Fortaleza são: Azul, Air France, Gol, Latam, KLM, Tap, TACV, Condor e Sideral. Os modelos de aeronaves que tais companhias aéreas operam no aeroporto são: A319, A320, A321, A32A, A332, A339, A343, B737, B73H, B752, B763, B76W e E195. Há, no total, 913 voos semanais, sendo 456 voos de origem do aeroporto de Fortaleza e 457 voos de chegada por semana. A quantidade de voos realizados por empresa semanalmente pode ser observada na Tab. 3 , a seguir.

Tabela 3 - Quantidade média de voos semanais operados por companhia aérea no aeroporto.

\begin{tabular}{cc}
\hline Empresa & Número de voos semanais \\
\hline Azul & 200 \\
Air France & 6 \\
Gol & 286 \\
Latam & 379 \\
KLM & 8 \\
TAP & 14 \\
TACV & 6 \\
Condor & 2 \\
Sideral & 12 \\
\hline
\end{tabular}

Fonte: FRAPORT, 2019.

\section{1 Aviação regional}

A aviação regional é responsável por atender aos municípios que fogem da região metropolitana (PEREIRA, 2018. De acordo com o Pinheiro (2019), os estudos para a atração de novos operadores da malha aérea priorizam as seguintes opções semanais: três voos da capital cearense a São Benedito (SWBE) e Crateús (SNWS), três a Iguatu (SNIG), três a Aracati (SNAT), cinco a Jericoacoara (SBJE) e cinco a Sobral (SNOB). Enquanto que os terminais de Sobral e de São Benedito já começaram a operar voos diretos para a capital em setembro de 2019 e a proposta é realizar os vôos em aeronaves menores (como o modelo Cessna Caravan, utilizado pela Two Flex, que tem capacidade para doze passageiros) (AVIAÇÃO CEARÁ, 2019). A Figura 4, a seguir, mostra as rotas com origem ou destino de voos regionais do aeroporto de Fortaleza com as respectivas siglas ICAO dos aeroportos.

Figura 4 - Malha aérea regional do aeroporto.

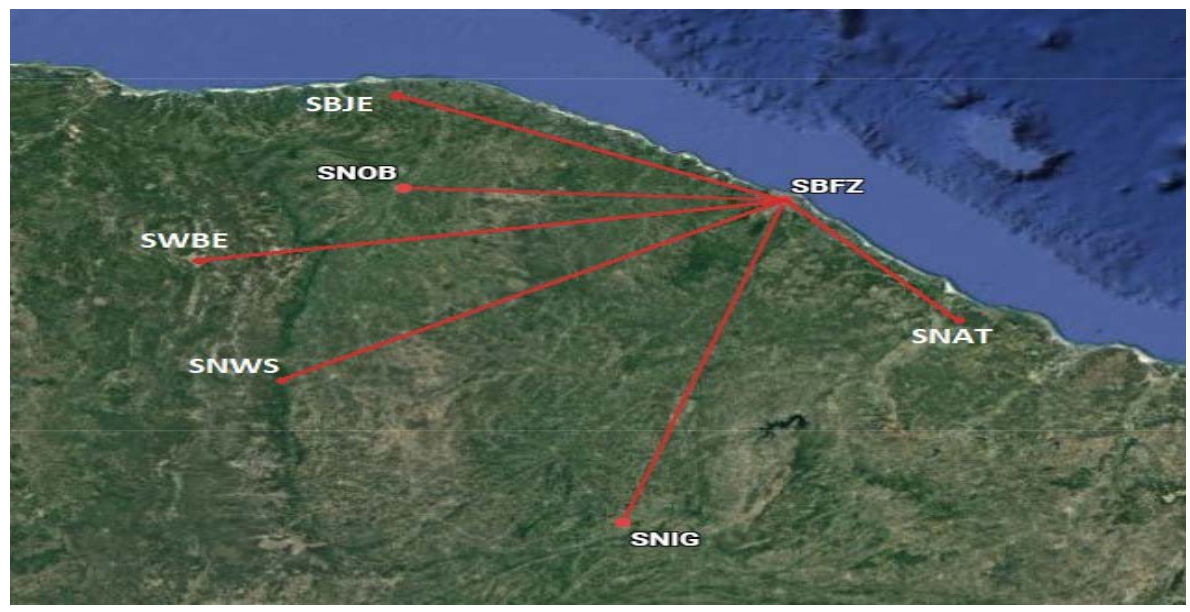

Fonte: Englund, 2019. 


\section{2 Aviação nacional}

A partir da Aviação Ceará, o aeroporto de Fortaleza terá destino para quinze estados, sendo o estado de São Paulo o único que terá mais de um aeroporto, totalizando três, sendo eles: Campinas (SBKP), Congonhas (SBSP) e Guarulhos (SBGR). Os outros destinos serão Belém - PA (SBBE), Belo Horizonte - MG (SBCF), Brasília - DF (SBBR), Curitiba - PR (CBCT), Rio de Janeiro - RJ (SBRJ), Manaus - AM (SBEG), Natal RN (SBSG), Porto Alegre - RS (CBPA), Recife - PE (SBRF), Salvador -BA (SBSV), São Luís - MA (SBSL), Teresina - PI (SBTE), Vitória - ES (SBVT), Juazeiro do Norte - CE (SBJU) (AVIAÇÂO CEARÁ, 2019). A Figura 5, a seguir, mostra as rotas com origem ou destino de voos nacionais do aeroporto de Fortaleza com as respectivas siglas ICAO dos aeroportos.

Figura 5 - Malha aérea doméstica do aeroporto.

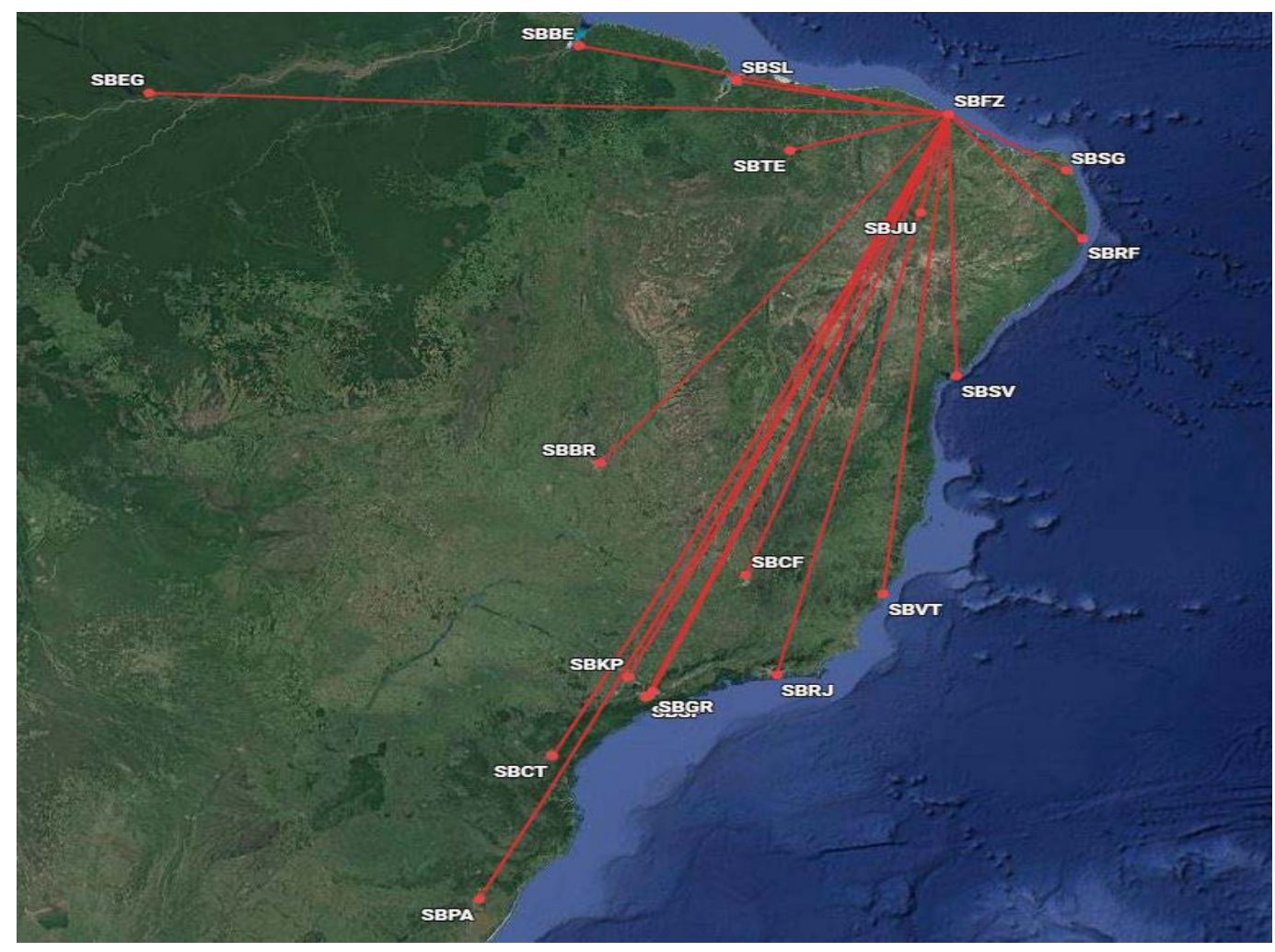

Fonte: Englund, 2019.

\section{3 Aviação internacional}

A aviação internacional só foi possível graças às $9^{\circ}$ liberdades do ar, que permitem o tráfego de aeronaves por países diferentes da nação de origem da companhia aérea, sem colocar em questionamento a soberania dos países que a aeronave decola, sobrevoa e pousa. É notório visualizar que existem conexões para três dos seis continentes do mundo, o que se deve ao fato da capital cearense possuir uma localização geográfica privilegiada. A Aviação Ceará informa que os voos internacionais terão como destino onze países, sendo os Estados Unidos o único país com mais de um aeroporto, totalizando dois: Orlando (KMCO), com voos diários, e Miami (KMIA), com voos de duas companhias, uma com voos diários e outra com cinco voos semanais. Os outros destinos são: Caiena - Guiana Francesa (SOCA), com voos aos domingos; Bogotá - Colômbia (CKBO), com voos aos sábados; Frankfurt - Alemanha (EDDF), com voos às sextas, que teve seus últimos voos, no mês de setembro de 2019; Lisboa - Portugal (LPPT), com voos diários e, na baixa estação, seis vezes na semana; Praia - Cabo Verde (GVNP), com voos nas segundas e quartas; Buenos Aires - Argentina (SAEZ), 
com voos aos sábados; Paris - França (LFPG), com três voos na semana; Amsterdã - Holanda (EHAM), com quatro voos semanais; Cidade do Panamá - Panamá (MPTO), com voos às segundas e, em alta estação, dois voos; Madrid - Espanha (LEMD), com dois voos semanais. Também há voos sazonais para Córdoba (SACO) e Rosário (SAAR) na Argentina (AVIAÇÃO CEARÁ, 2019). A Figura 6, a seguir, mostra as rotas com origem ou destino de voos internacionais do aeroporto de Fortaleza com as respectivas siglas ICAO dos aeroportos.

Figura 6 - Malha aérea internacional do aeroporto.

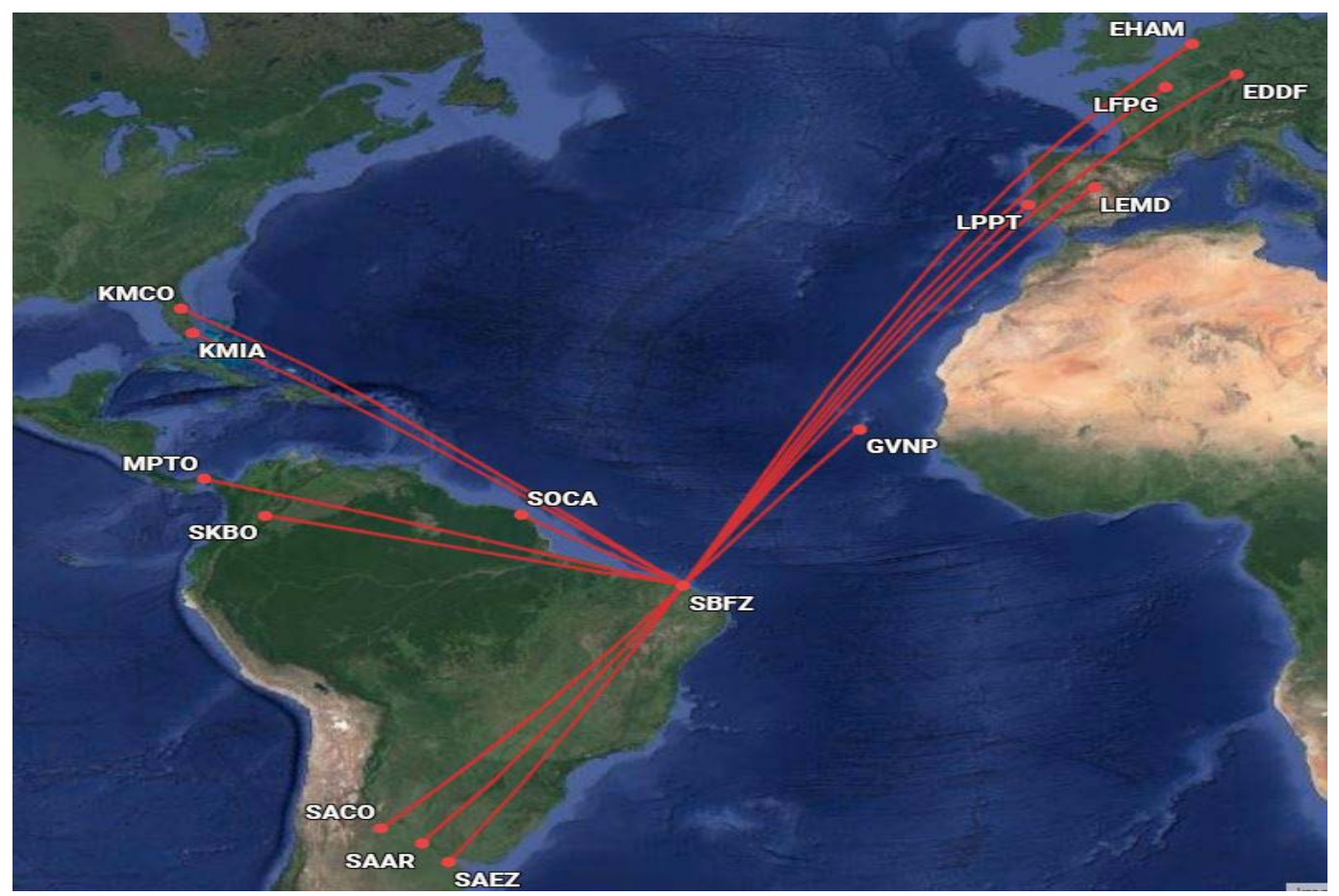

Fonte: Englund, 2019.

\section{Conclusão}

A partir do estudo da infraestrutura do aeroporto de Fortaleza após a sua privatização, que culminou na reforma de ampliação, foram realizadas melhorias no parque aeroportuário, com a revitalização e incrementação nos sistemas já existentes, o que proporcionou um melhor atendimento da demanda crescente e dos serviços prestados pelo aeroporto, gerando indicadores positivos. Paralelo a isso, novas rotas entraram na lista do aeroporto, como rotas internacionais e regionais, que implementaram a importância e abrangência do aeroporto tanto no cenário nacional quanto internacional.

Existe forte indício de que o rumo da aviação civil no Brasil como um todo depende, principalmente, do comportamento da economia do país, de modo mais específico do crescimento do PIB e do fomento da economia (BARAT, 2012).

Segundo o Pinto (2015), no relatório 1 de estudos de mercado, realizado no ano de 2015 no parque aeroportuário de Fortaleza, existe uma previsão de demanda do PAX total que anuncia um crescimento de 6,9 milhões no ano de 2017, isto é, no início da concessão, para 27,8 milhões em 2046, ao final da concessão, com um Compound Annual Growth Rate (CAGR) de 4,9\% ao ano. Por meio dessa estimativa, o valor de passageiros total praticamente irá quadruplicar, mostrando a necessidade de se destinar recursos para inovações futuras do parque aeroportuário com o objetivo de garantir o fluxo adequado nos serviços prestados.

Em um mundo onde a economia torna-se cada vez mais globalizada, para competir no mercado internacional, são necessários investimentos continuados em aumento da capacidade, pensando-se já nas 
perspectivas futuras, em longo prazo, assim como também é necessário implementar tecnologias que já existem no mundo inteiro e continuar buscando inovações.

Com relação à infraestrutura aeroportuária de Fortaleza, é crucial levar em consideração a tendência mundial dos avanços tecnológicos e as mudanças de mercado, que são flutuantes. Obter dados a partir do sistema de processamento de transação (SPT), a partir do tratamento e processamento dos dados, é possível fazer um planejamento tático por intermédio do sistema de informações gerenciais (SIG). E, por fim, com o sistema de apoio à decisão (SAD), tomar decisões estratégicas que garantam o bom gerenciamento do aeroporto e alavanquem o aumento da demanda de passageiros, mas mantendo a qualidade e eficiência no serviço prestado.

\section{Referências}

AGÊNCIA NACIONAL DE AVIAÇÃO CIVIL. Anuário estatístico operacional: 2018. Brasília: ANAC, 2018. AGÊNCIA NACIONAL DE AVIAÇÃO CIVIL. Contrato de concessão para ampliação, manutenção e exploração do aeroporto internacional de Fortaleza - Pinto Martins. Brasília: ANAC, 2019. 59 p. AGÊNCIA NACIONAL DE AVIAÇÃO CIVIL. RBAC 139: regulamento brasileiro da aviação civil. Brasília: ANAC, 2012.

AGÊNCIA NACIONAL DE AVIAÇÃO CIVIL. RBAC 154: regulamento brasileiro da aviação civil. Brasília: ANAC, 2019.

AVIAÇÃO Ceará: novo destino a bordo. Fortaleza, Ce: O Povo, Fortaleza, 26 fev. 2019. Disponível em: \&lt;https://digital.opovo.com.br/aviacaoceara\&gt. Acesso em: 31 jul. 2019.

BANCO NACIONAL DE DESENVOLVIMENTO. Estudo do setor de transporte aéreo do Brasil: relatório consolidado. Rio de Janeiro: McKinsey\&Company, 2010. 380p

BARAT, Josef. Globalização logística e transporte aéreo. São Paulo: Senac, 2012. 268 p.

BRASIL. Ministério da Infraestrutura. Hórus. Brasília:Ministério da Infraestrutura,2018. Disponível em: http:// www.infraestrutura.gov.br/rede-aeroportos.html. Acesso em: 26 out. 2019.

DANTAS, Eustógio Wanderley Correia. Construção da imagem turística de Fortaleza/Ceará. Revista de Geografia da UFC, Fortaleza, v. 1, n. 1, p.54-60, 2002.

ENGLUND, Markus. Great Circle Map:imagensNASA terrametrics. 2017. Disponível em: https://www. greatcirclemap.com/. Acesso em: 17 ago. 2019.

FALCÃO, Viviane Adriano. Demanda aeroportuária de Manaus e sua influência para o setor de turismo da região. JournalOfTransportLiterature, Manaus, v. 7, n. 1, p.127-146, jan. 2013.

FRANCISCO, Wagner de Cerqueria e. A economia do Ceará. Brasil Escola. Disponível em: https:// brasilescola.uol.com.br/brasil/a-economia-ceara.htm. Acesso em 22 set 2018.

FRAPORT. Fortaleza Airport: 2019. Disponível em: https://fortaleza-airport.com.br/pt/. Acesso em: 19out. 2019.

IBGE. Produto Interno Bruto dos estados e municípios - PIB. Rio de Janeiro: IBGE, 2018. Disponível em: https://www.ibge.gov.br/explica/pib.php. Acesso em: 12 nov. 2019.

INFRAERO.Histórico do Aeroporto. Brasília:Infraero,2017. Disponível em:https://web.archive.org/ web/20170904215411/http://www4.infraero.gov.br/aeroportos/aeroporto-internacional-de-fortaleza-pintomartins/sobre-o-aeroporto/historico/. Acesso em: 2 out. 2019.

INFRAERO. Projeto de expansão do Aeroporto de Fortaleza. Diário do Nordeste, Fortaleza, 1 fev.2019. Disponível em: https://diariodonordeste.verdesmares.com.br/editorias/negocios/online/confira-detalhes-doprojeto-de-expansao-do-aeroporto-de-fortaleza-1.2057713. Acesso em: 02 out. 2019. 
LIMA, Nathana Alcântara. Análise econométrica aplicada ao planejamento de infraestrutura aeroportuária: Estudo de caso do aeroporto de Vitória. Revista Tecnologia, Fortaleza, v. 34, n. 1 e 2, p.104-112, dez. 2013.

MELO, David Lincoln de Sousa. Análise da capacidade do terminal de passageiros do aeroporto internacional Pinto Martins em função de modificações na geometria da pista de pouso e decolagem. 2017.77f. Trabalho de Conclusão de Curso (Bacharelado em Engenharia Civil) - Centro de Tecnologia, Universidade Federal do Ceará, Fortaleza, 2017.

PEREIRA, Alexis Zanoni Vasconcelos Rodrigues. Análise comparativa de modelos de aeronaves comerciais concorrentes de mercado que tem como nicho a aviação regional através de projeções de rotas na região nordeste e no estado do Ceará envolvendo aeroportos regionais e sistêmicos. 2018. 58f. Trabalho deConclusão de Curso (Bacharelado em Engenharia Mecânica) - Centro de Ciências Tecnológicas, Universidade de Fortaleza, Fortaleza, 2018.

PINHEIRO, Yohanna, Governo planeja novos incentivos para aviação regional no Estado. Diário do Nordeste. Fortaleza, 1 mar.2019. Caderno Negócios. Disponível em: https://diariodonordeste.verdesmares. com.br/editorias/negocios/governo-planeja-novos-incentivos-para-aviacao-regional-no-estado-1.2070031. Acesso em: 30 jul. 2019.

PINTO, Marcos (coord.). Relatório 1:estudos de mercado: aeroporto internacional Pinto Martins. Fortaleza, 2015. 206p.

SOARES, Rogério Barbosa et al. (org.). Indicadores Econômicos do Ceará. Fortaleza: Ipece, 2017. p.1.Disponível em: https://www.ipece.ce.gov.br/wp-content/uploads/sites/45/2019/02/Indicadores Economicos_2013_a_2017.pdf. Acesso em: 11 jan. 2020.

\title{
Sobre os Autores
}

\section{Bruno da Silva Sales}

Graduação em andamento pela Universidade de Fortaleza em Engenharia Civil.

\section{Paulo Victor Carneiro Araujo}

Graduação em andamento pela Universidade de Fortaleza em Engenharia Civil.

\begin{abstract}
Nelson Bezerra Ferreira Júnior
Mestre profissional em engenharia aeronáutica MP-Safety, pelo Instituto Tecnológico de Aeronáutica (ITA) no ano de 2019. Possui especialização em análise organizacional pela Faculdade Getúlio Vargas (FGV) em 2005. Bacharel em Engenharia Mecânica pela Universidade Federal do Ceará (UFC) no ano de 1995. Possuindo experiência na área de Engenharia Mecânica, com ênfase em processos de fabricação, engenharia de produção e gestão empresarial, operações industriais, gestão de projetos de melhoria, planejamento estratégico e educação a nível superior. Atualmente é professor do Centro de Ciências Tecnológicas da Universidade de Fortaleza (Unifor).
\end{abstract}

\section{Viviane Adriano Falcão}

Doutora em Engenharia de Transportes pela Universidade Federal do Ceará (UFC) no ano de 2016. Mestre em Engenharia de Infra-Estrutura Aeronáutica pelo Instituto Tecnológico de Aeronáutica (ITA) em 2012. Bacharel em Engenharia Civil pela Universidade Federal do Ceará (UFC) no ano de 2007. Tem experiência na área de Engenharia Civil, com ênfase em Engenharia de Transportes, atuando principalmente nos seguintes temas: aeroportos, econometria, transporte aéreo e pesquisa operacional. Atualmente é professora do departamento de Engenharia Civil da Universidade Federal de Pernambuco (UFPE).

Recebido em 04.05.2020

Aceite em 28.07.2020 